Summer 8-24-2019

\title{
Identifying Opportunities for the Role of Occupational Therapy in a Correctional Setting
}

Maxwell Sand

DOI: https://doi.org/10.46409/sr.VMIB8502

Follow this and additional works at: https://soar.usa.edu/capstones

Part of the Occupational Therapy Commons

\section{Recommended Citation}

Sand, M. (2019). Identifying Opportunities for the Role of Occupational Therapy in a Correctional Setting. [Doctoral project, University of St Augustine for Health Sciences]. SOAR @ USA: Student Capstone Projects Collection. https://doi.org/10.46409/sr.VMIB8502

This Capstone is brought to you for free and open access by the Student Research at SOAR @ USA. It has been accepted for inclusion in Student Capstone Projects by an authorized administrator of SOAR @ USA. For more information, please contact soar@usa.edu, erobinson@usa.edu. 
IDENTIFYING OPPORTUNITIES FOR THE ROLE OF OCCUPATIONAL THERAPY IN A CORRECTIONAL SETTING

by

Maxwell K. Sand

A Capstone Project Proposal Presented in Partial Fulfillment of the Requirements for the Degree of DOCTOR OF OCCUPATIONAL THERAPY

University of St. Augustine for Health Sciences

August, 2019 
IDENTIFYING OPPORTUNITIES FOR THE ROLE OF OCCUPATIONAL THERAPY IN A

\section{CORRECTIONAL SETTING}

by

Maxwell K. Sand

has been approved

August, 2019

APPROVED:

Erin Schwier EdD., OTR/L, Program Director

Susan MacDermott, OTD, OTR/L, Doctoral Coordinator

ACCEPTED AND SIGNED:

eschwier@usa.edu $\begin{aligned} & \text { Digitally signed by eschwier@usa.edu } \\ & \text { DN: cn=eschwier@usa.edu } \\ & \text { Date: 2019.08.21 11:24:42-07'00' }\end{aligned}$

Erin Schwier, EdD., OTD, OTR/L, Program Director

dusem Muchenct

Susan MacDermott, OTD, OTR/L, Doctoral Coordinator 
Table of Contents

CHAPTER I. Introduction $\quad 5$

Background 5

Statement of the Problem 6

Purpose Statement $\quad 8$

Rationale for Proposed Project 8

Significance of the Proposed Project 9

Preliminary Project Objectives 9

Definition of Terms 9

$\begin{array}{ll}\text { Assumptions, Limitations, and Delimitations } & 10\end{array}$

CHAPTER II. Literature Review 11

Occupational Therapy's Role $\quad 11$

Correctional Staff Health 12

Models and Theories 13

CHAPTER III. Project Description 15

$\begin{array}{ll}\text { Proposed Methods and Timeline } & 15\end{array}$

$\begin{array}{ll}\text { Facility } & 16\end{array}$

$\begin{array}{ll}\text { Participants } & 16\end{array}$

$\begin{array}{ll}\text { Study Design } & 16\end{array}$

$\begin{array}{ll}\text { Methods of Data Collection } & 17\end{array}$

$\begin{array}{ll}\text { Procedures/Timelines } & 17\end{array}$

$\begin{array}{ll}\text { Planned Analysis and Envisioned Next Steps } & 18\end{array}$

$\begin{array}{ll}\text { Actual Methods and Timeline } & 19\end{array}$

$\begin{array}{ll}\text { Study Design } & 19\end{array}$

$\begin{array}{ll}\text { Participants } & 20\end{array}$

Methods of Data Collection 20

CHAPTER IV. Results and Analysis 21

Data Analysis 21

$\begin{array}{ll}\text { Results } & 21\end{array}$ 
CHAPTER V. Discussion \& Conclusion 27

$\begin{array}{ll}\text { Discussion } & 27\end{array}$

Limitations $\quad 29$

Implications for Occupational Therapy $\quad 30$

Conclusion 33

$\begin{array}{ll}\text { References } & 34\end{array}$

Appendix A. Proposed Observational Data Collection Form 38

Appendix B. Proposed Staff Interview Questions 40

Appendix C. Proposed Resident Interview Questions 42

Appendix D. Email Script $\quad 44$

Appendix E. Actual Interview Questions 46

Appendix F. Instructions for Journal Publication 50 


\section{CHAPTER I}

\section{Introduction}

\section{Background}

In a recent TED Talk this past March, Adam Foss, a juvenile justice reformer and prosecutor shared his vision for a better justice system. In his presentation, Foss reports that 80 billion dollars are spent each year on our prison system today (Foss, 2016). Due to the enormous cost of incarceration, Foss suggests reallocating that money for prevention work in education, mental health services, and substance abuse treatment programs. According to Foss, these interventions could prevent crime to invest in community betterment. Aside from the billions of dollars spent on our prison system today, the greater issue lies in our society's inability to recognize the needs of the incarcerated population.

It is known that the United States leads the world with the highest rates of incarceration (World Prison Brief, 2019). There are over 2 million men and women incarcerated in the US; which equates to about 1 in every 100 Americans (Bureau of Justice Statistics, 2016). Unfortunately, these numbers are approximately 6 times greater than those in Canada, Australia, and Spain; 7-8 times higher than France and Italy; and 15 times higher than Japan (The Sentencing Project, 2017). According to the National Institute of Justice (2018), recidivism is measured by criminal acts that result in rearrests, reconviction, or return to prison during a threeyear period following the prisoner's release. In a longitudinal study that tracked over 400,000 prisoners in 30 states after their release from 2005 to 2014, Durose, Cooper, and Snyder, (2014) found that approximately two-thirds of released prisoners were rearrested within three years of release and about $77 \%$ within five years of release. This data reflects a criminal justice system that fails to recognize this population's needs to make a change in their behavior. 
High rates of recidivism are also linked to a lack of necessary skills for the successful reintegration into society. Crabtree, Ohm, Wall, and Ray, (2016) found that these "challenges are often deeply rooted in past lived experiences and circumstances such as homelessness, limited marketable work experience, intellectual disabilities, poor education, mental health conditions, little to no family support, affiliation with gangs, or a history of substance abuse" (Crabtree et al., 2016, p. 402)

Eggers, Muñoz, Sciulli, and Crist, (2006) provides one of the most complete descriptions of occupational therapy programming in a county jail. These authors describe "The Community Reintegration Project”, as the first successful attempt at bringing an Occupational Therapy program into a county jail. This collaboration grew out of a partnership between the faculty at the University of Duquesne's department of occupational therapy, the correctional staff at the Allegheny County Jail, and Goodwill Industries of Pittsburgh. Its program was designed to decrease recidivism and support successful community reintegration by focusing on the areas of wellness, family, support structure, skills for living, education, and employment. The program structure consisted of both group and individual interventions while the resident was incarcerated and followed the resident for 1-year post-release to support successful reintegration. Each resident in prison had an individualized re-integration plan which identified specific and realistic goals for each domain area. Preliminary outcome data from this study has demonstrated success in reducing recidivism and helping individuals acquire and maintain employment following release.

\section{Statement of the Problem}

When looking at the incarcerated population, having a criminal record may disqualify many of these individuals from gaining employment, which sets in motion a cycle that defines 
the high rates of recidivism (Yuancie, 2017). The stigma that comes with having a criminal record can also be devastating to one's image and self-esteem, thereby adding yet another barrier to their successful reintegration into society (Crabtree et al., 2016). Unemployment drastically limits an individual's ability to provide stable housing and safe living conditions. Without an ability to meet even the most basic needs, an individual may be more likely to commit a crime to simply to sustain themselves.

Correctional staff members face their own set of challenges associated with their profession such as heavy stress, fatigue and feelings of burnout that can incidentally impact inmates (Gould, Watson, Price, \& Valliant, 2013). Morgan (2009) noted that correctional officers experience significantly higher rates of suicide than both the general public and police officers. Furthermore, these symptoms are known to be linked to a myriad of factors including, but not limited to: "the threat of violence or injury posed by inmates, the physical and mental health needs of inmates, working in a closed or restricted environment with limited access to outdoors and natural lighting, the physicality of the job, and having to be in a constant state of alertness" (Brower, 2013, p. 5).

Given that occupational therapy in the U.S. criminal justice system remains an emerging practice area, occupational therapy practitioners have begun slowly addressing the unmet needs of this underserved population. However, the amount of specific program descriptions and outcome studies are limited (O’Connell \& Farnworth, 2007). With the U.S. leading the world in rates of incarceration and high levels of recidivism, occupational therapy practitioners must strive to establish a stronger presence through consistent and increased application of specific practice models to effectively implement interventions that include valid and reliable assessments tools for measurable outcomes (Muñoz, Moreton \& Sitterly, 2016). With the 
discovery of new evidence-based knowledge, further arguments can be made to support the notion that occupational deprivation negatively influences health and wellbeing for residents and correctional staff, alike. Meanwhile occupational enrichment supports job satisfaction for the staff and successful reentry for residents (Munoz, 2011).

\section{Purpose Statement}

This capstone aims to evaluate the specific needs and concerns of the residents and staff at a community correctional facility to provide insight into the challenges they face within their environment and the skills necessary for occupational enrichment. Therefore, the purpose of this capstone is twofold: 1) To identify strengths and barriers relative to the residents' engagement in health-promoting roles, routines, and occupations; and 2) To identify the needs of correctional staff members in addressing their health and wellness, given the interconnected nature of resident and staff relationship.

\section{Rationale for the Proposed Project}

Occupational therapists have the opportunity to influence the health of individuals, populations, and organizations through collaboration, education, and advocacy. Occupational therapy can also improve the physical, mental, and social aspects of individual's lives and work to implement change by examining factors associated with overcoming barriers and enhance occupational performance (AOTA, 2014).

The theoretical basis of this capstone project will be supported by concepts grounded in the Model of Human Occupation (MOHO) as this framework considers how each individual's occupational performance is driven by volition and habituation (Boyt Schell, Gillen, Scaffa, \& Cohn, 2014). Additionally, the Person-Environment Occupation (PEO) model is another framework which is applicable to this capstone as this framework considers how each individual 
can be influenced by their institutional and/or physical environmental contexts (Muñoz, Moreton \& Sitterly, 2016). Previous studies within the criminal justice literature have also mentioned utilizing these practice frameworks in the selection and structuring of assessments and programs that effectively addressed the needs of this population (Munoz, 2011). The application of the MOHO and PEO within the criminal justice setting will be further expanded upon in the literature review section of this paper.

\section{Significance of the Proposed Project}

This study will be significant in determining the possible future impact of the programming at correctional facilities to address the high rates of recidivism. This capstone project aims to contribute to the evolution of occupational therapy practice in the forensic setting through advocacy and/or the development of programs for this unique population. By increasing awareness to the negative effects occupational deprivation can have on the health and wellbeing of residents and correctional staff alike, opportunities for occupational enrichment can be identified to support job satisfaction for staff and successful reentry for residents.

\section{Preliminary Project Objectives}

- Observe and assess the state of the current programming at a correctional facility.

- Explore workplace operations with the residents and staff members.

- Perform a needs assessment with the residents and staff to inform OT practice opportunities

- Describe the needs of residents and staff in order to enhance successful community reintegration.

\section{Definitions of Terms}


- Community-based correctional setting is defined as a residential or nonresidential setting where offenders are sent as an alternative to incarceration.

- Community re-entry centers are defined as institutions that provide a structured and supervised residential setting for offenders just prior to or after their release from prison. These settings assist residents with reintegration planning, job placement, and financial management; help them to locate permanent housing; and connect them with community services that can support their return to the community (Munoz, 2011).

- Community reintegration planning is defined as planning an offender's return to the community in a law-abiding role. Ideally, community reintegration planning should begin when the person is incarcerated, follow the offender through release, and include the provision of aftercare (Munoz, 2011).

- Forensic setting is defined as any setting pertaining to or connected with the correctional system.

- Halfway or transitional house can be defined as a transitional facility where the offender lives and is involved in school, work, training, and more, while preparing for reentry to the community.

- Recidivism refers to a repetition of criminal behavior resulting in a return to incarceration. (Munoz, 2011).

- Residents are defined as individuals in prison who has committed an illegal act.

- Work furlough is a correctional program which allows residents who are nearing discharge, to temporarily leave the institution for the purpose of continuing regular employment during the day but returning to confinement on nights and weekends.

\section{Assumptions, Limitations, and Delimitations}


This study will be based under the assumption that residents have occupational needs or limitations to succeed in community reintegration including skills for living, marketable work experience for gaining and maintaining employment, family support, education, and resources. Additionally, surveys and interviews will rely upon on the participants' honest reports. It is also important to note that the residents' satisfaction and success are likely to be affected by the quality of the staff's stress and/or satisfaction levels.

Limitations of this study that may exist would be the small sample size which can limit the power of inferences with respect to a larger population and convenient sampling methods may limit generalizability due to a lack of randomization. Lastly, the participants' experiences may be dependent on the particular correctional facility.

Specific choices were made regarding this research topic such as the population, frames of reference, and the duration which all act as delimitations to this study. As a result, all preliminary objectives have been self-chosen and based upon answering specific questions posed by the topic of interest. As such, assessment of the residents, staff, and environment will focus on expanding one's understanding of a particular facility and the residents' occupational needs and barriers.

\section{CHAPTER II}

\section{Literature Review}

\section{Occupational Therapy's Role}

Current literature confirms that the role of occupational therapy within the forensic setting continues to be an emerging practice area. According to a scoping review of relevant literature from eight research databases and occupational therapy textbooks published between 
1968-2016, one hundred sources were analyzed to identify common themes that comprised of addressing assessments, program descriptions, and asserting for the establishment of occupational therapy in the criminal justice setting (Muñoz et al., 2017). Unfortunately, practice guidelines for OT in these settings are currently nonexistent. Thus, the occupational perspective on community reentry and engagement in productive occupations is needed.

In a recent pilot study evaluating a prison's occupational therapy informal education program, Crabtree et al., (2016) found that when participants had the opportunity to choose their own educational topics instead of topics being chosen for them, they felt an increased sense of self-worth. Similarly, when Corring and Cook, (1999) viewed the perspectives of individuals with a history of mental illness and experiences with the mental health service delivery system, they discovered that the participants' primary concern was to be viewed as valuable human beings by the service providers and by society. To address these circumstances, programming in the forensic setting should fall in line with occupational therapy guidelines and aim to be clientcentered to establish good rapport, and a clear understanding of the client's lived experiences, expectations, and goals.

Eggers, Muñoz, Sciulli, and Crist (2006) indicate that successful community reintegration for inmates requires a skill-set that occupational therapists have long addressed in their domain of practice. Occupational therapists can provide client-centered group and individual sessions to facilitate the acquisition of life skills such as: "vocational exploration, goal setting, development of work-place interpersonal skills, job search strategies, and money management” (Eggers et al., 2006, p. 22).

\section{Correctional Staff Health}


According to Lehman, Greener, Rowan-Szal, and Flynn (2012), there is a high demand to increase the quantity and quality of treatment programs in correctional settings. Many barriers to effective treatment in prisons exist including: "inadequate assessments that do not assure that offenders receive the types of services they need the most; difficulty recruiting, training, and retaining qualified staff; frequent conflict between therapeutic and security concerns" (Lehman et al., 2012, p. 10). Additionally, with the vocational burden of correctional staff members found to be heavy, stressful, and fatiguing leading to feelings of burnout (Gould, Watson, Price, \& Valliant, 2013), job performance is likely to decline affecting the way in which staff members perform their duties and thereby negatively impacting the way in which they interact with residents in the correctional facility (Schaufeli \& Peeters, 2000).

Upon examining existing literature on occupational therapy's involvement with correctional facility staff members, Wagenfeld et al. (2017) explored the relationship between one's interaction with nature and self-perception of stress for correctional system staff. Results

found that correctional staff used time outdoors to cope with stress. Furthermore, the majority of correctional staff surveyed mentioned that they would benefit from an outside decompression area at their institution; this was especially the case for those who used outdoor time as a coping strategy and for those who preferred to go outside during their work breaks.

\section{Models and Theories}

A study by Muñoz, Moreton and Sitterly (2016), found that $37.5 \%$ of occupational therapy practitioners in the U.S. criminal justice settings did not utilize an occupational therapy practice model to guide their interventions. However, amongst those who did, the Model of Human Occupation (MOHO) was the most frequently used model, making up 29\% of respondents; followed by the Person-Environment Occupation Model (PEO), at 20\%. 
The MOHO is "an occupation-focused, theory-driven, client-centered, evidence-based approach to occupational therapy practice” (Boyt Schell, Gillen, Scaffa, \& Cohn, 2014). The concepts of MOHO strive to understand the individual's motives, routines, skills, and influences of the environment on their capacity to perform desired occupations.

Bowser, Link, Dickson, Collier, and Donovan-Hall (2017), provide insight into the experiences of boredom from the perspectives of eight men with psychosis detained in a secure unit. With restricted access to their community, friends, and family, participants described the way boredom was negatively impacting their mental health and motivation. These men also expressed concern for the lack of meaningful activities available to them, especially on weekends. Without access to meaningful occupations, establishing roles, routines, habits, and/or hobbies became a challenge, causing further frustration resulting in more violence and aggression (Bowser et. al., 2017). These findings highlight the influence volition and habituation have on occupational performance within social and physical environmental contexts. Therefore, the premises of $\mathrm{MOHO}$ will serve as an appropriate framework for gathering information about the residents' needs, limitations, and strengths to facilitate optimal occupational engagement leading to successful community reintegration.

The Person-Environment-Occupation Model (PEO) is another model which relies upon the belief that occupational performance is determined by the person, environment, and occupation. This model was developed to place emphasis on the environment as there was a tendency in the past for occupational therapists and practitioners from other disciplines to focus largely on personal factors while neglecting the significance of the environment on occupational performance (Boyt Schell et al., 2014). The PEO model emphasizes the fact that occupational performance must be understood within its varying contexts as the environment can either inhibit 
or permit occupational performance. As previously mentioned, correctional facilities are known to be restrictive environments that inhibits occupational performance for residents (Bowser et. al., 2017) as well as stressful environments that can cause fatigue and burnout for correctional staff members (Wagenfeld et. al., 2017). Thus, the application of this framework will be beneficial in gaining a greater understanding of the dynamic interrelationship between the person, environment, and occupation with an opportunity to enhance occupational skills for the residents along with job satisfaction for the staff members.

As both the MOHO and PEO models ground themselves in the examination of an individual's occupational performance within their unique environmental contexts, these two models will serve to support the theoretical basis of this capstone.

\section{CHAPTER III}

\section{Project Description}

\section{Proposed Methods and Timeline}

This section outlines the methods proposed to determine the perception of residents and staff at CoreCivic. In an effort to gain greater insight into the opportunities of occupational therapy as a form of intervention for enhancement of current programming, a needs assessment will be conducted, consisting of direct observation and interviews with both residents and staff members. Resulting data has the potential to identify strengths and barriers relative to the resident's engagement in health-promoting roles, habits, routines, and occupations. Additionally, this capstone will be significant in identifying the needs of correctional staff members in addressing their health and wellness, given the interconnected nature of resident and staff relationship. 
Facility. CoreCivic is a privately held community corrections company based in San Diego, California. The 26-year-old company operates two facilities totaling more than 600 beds, serving the Federal Bureau of Prisons and San Diego County. This organization provides costeffective solutions for housing and rehabilitation through community corrections specializing in work furloughs, residential reentry programs, and home confinement. CoreCivic has agreed to participate in this project and will work in collaboration with this capstone project in gaining access to staff and facility residents in order to carry out this needs assessment.

Participants. Staff members and eligible residents will be recruited using a convenience sampling design. This sampling method is most appropriate given the brief study period as it also increases the basis of participant availability (Portney \& Watkins, 2015). Participation will be voluntary, and each subject will be assigned a number for confidentiality. Interview responses will be kept anonymous and data will be stored by the researcher in a password protected electronic format. Additionally, no personal information will be shared with other residents or facility personnel.

Study Design. This research will employ a phenomenological approach to examine the detailed views of the residents and staff in an effort to provide a deeper understanding of their lived experiences and occupational needs. This approach is most appropriate for this capstone as it "seeks to draw meaning from each individual's complex realities through careful analysis of first-person narrative materials" (Portney \& Watkins, 2015, p. 307). Observations will be performed by the researcher as a complete observer as Creswell (2014), mentioned this type of observation is most useful and advantageous in exploring topics that may be uncomfortable for participants to discuss. Upon permission and consent from the facility and participants, the researcher will conduct semi-structured, face-to-face individual and/or focus group interviews to 
elicit views and opinions from participants (Creswell, 2014). Interview sessions will be audiorecorded and transcribed verbatim to afford the researcher greater ease in tracking recurring words, phrases, and ideas.

Methods of Data Collection. Methods of data collection will include observation and semi-structured interviews to gather qualitative data. Observational data will be obtained through field notes taken by the researcher and recorded during observation. Descriptive notes will include details of the participant relative to the specifics of demographics such as the time, place, date, environmental characteristics, and the accounts of particular events or activities such as the occupations discussed and performed; meanwhile reflective notes will consist of the researcher's personal thoughts and ideas (Creswell, 2014). The Model of Human Occupation (MOHO) has been identified as the most commonly used theory to support the use of data collection tools within the forensic setting (Duncan, Munro, \& Nicol, 2003). Thus, interview questions within this capstone have been influenced by other interview tools grounded in the MOHO such as the Occupational Profile Template and the Occupational Performance History Interview II (OPHI II). These tools have been adapted and tailored in accordance with knowledge from the literature to identify the unique needs of residents and staff of this facility. *See Appendix A for observational data collection form, Appendix B for staff interview questions, and Appendix C for resident interview questions.

Procedures/Timelines. This study will be carried out over a 16-week period (Table 1). During this time, specific objectives will be met according to a timeline. The following procedures will be used for this study: The first four weeks will consist of observation and assessment of the current programming at the site. A needs assessment of the residents and staff members will also begin at this time. Collection of qualitative data through observations and 
interviews will start throughout the next eight weeks. During this time, the researcher will also begin analyzing data and deriving themes through transcript coding and thematic analysis. Lastly, the remainder of the time will be allotted for assessing and prioritizing their unique needs.

Table 1. Timeline of Project Objectives

\begin{tabular}{|l|c|c|c|c|}
\hline \multicolumn{1}{|c|}{ Objectives } & \multicolumn{3}{c|}{ Timeline } \\
\cline { 2 - 5 } & $3 / 25-4 / 25$ & $4 / 26-5 / 26$ & $5 / 27-6 / 27$ & $6 / 28-8 / 16$ \\
\hline $\begin{array}{l}\text { Observation and assessment of the } \\
\text { current programming. }\end{array}$ & $\mathrm{X}$ & $\mathrm{X}$ & $\mathrm{X}$ & $\mathrm{X}$ \\
\hline $\begin{array}{l}\text { Explore workplace operations with the } \\
\text { residents and staff. }\end{array}$ & $\mathrm{X}$ & $\mathrm{X}$ & $\mathrm{X}$ & \\
\hline $\begin{array}{l}\text { Perform a needs assessment with the } \\
\text { residents and staff to inform OT practice } \\
\text { opportunities. }\end{array}$ & $\mathrm{X}$ & $\mathrm{X}$ & & $\mathrm{X}$ \\
\hline $\begin{array}{l}\text { Describe the needs of residents and } \\
\text { workforce in order to enhance successful } \\
\text { community reintegration. }\end{array}$ & & & & \\
\hline
\end{tabular}

\section{Planned Analysis and Envisioned Next Steps}

Data analysis for this project will consist of transcript coding to identify common themes and concepts derived from the transcribed data. Thematic analysis will then be used to interpret and derive meanings for inferences can be made. Through this analysis, the researcher seeks to understand the underlying meaning of the words and concepts that were described by the participants. Sufficient data collection will be determined once saturation occurs. Saturation occurs when there is a lack of newly emerging themes or concepts during the data collection process. Upon completion of data analysis, the researcher will describe the results on a written manuscript and disseminate data through an avenue most suitable for its varying audiences (e.g. poster boards, PowerPoint presentation, handouts and/or pamphlets) to advocate for the role of occupational therapy in forensic settings. 


\section{Actual Methods and Timeline}

A recent change in the facility's ownership from the formerly known "CAI"

(Correctional Alternatives Incorporated) to what is now called "CoreCivic" (a corporate organization) resulted in the site requiring more time to approve the aforementioned capstone experience. Due to this unforeseen circumstance, the direction of this research changed into a qualitative study examining the experiences of individuals who previously worked in or currently work in correctional facilities, in an effort to gain an understanding of their lived experiences and occupational needs, different roles, and workplace culture through their perspectives. The title of this study has thus been modified to "Assessing Workplace Wellness in Correctional Settings." As a subset of this study, a scoping review of relevant literature was conducted identifying articles associated with trauma and/or trauma-informed care in the correctional setting. The following table outlines the actual timeline and objectives carried throughout this study.

\begin{tabular}{|l|c|c|c|c|}
\hline \multicolumn{1}{|c|}{ Objectives } & \multicolumn{3}{c|}{ Timeline } \\
\cline { 2 - 5 } & $4 / 01-4 / 30$ & $5 / 01-5 / 31$ & $6 / 01-6 / 30$ & $7 / 01-8 / 16$ \\
\hline $\begin{array}{l}\text { Applied sound reasoning and evaluation } \\
\text { of research examining factors associated } \\
\text { with trauma and trauma-informed care in } \\
\text { correctional settings. }\end{array}$ & $\mathrm{X}$ & & & \\
\hline $\begin{array}{l}\text { Engaged in professional communication } \\
\text { with study participants for recruitment } \\
\text { process. }\end{array}$ & & & $\mathrm{X}$ & \\
\hline $\begin{array}{l}\text { Conducted semi-structured interviews } \\
\text { with correctional staff participants. }\end{array}$ & & & & \\
\hline $\begin{array}{l}\text { Analyzed evidence and data for the } \\
\text { advancement of OT practice in the } \\
\text { forensic setting. }\end{array}$ & & & $\mathrm{X}$ & \\
\hline
\end{tabular}

Study Design. This research employed a phenomenological approach to examine the diverse views of correctional staff members in the effort to provide a deeper understanding of their lived experiences and occupational needs. Approval from the IRB committee at the 
University of St. Augustine was granted for this study, and upon permission and consent from the participants, research was conducted in semi-structured individual interviews to elicit views and opinions from participants. Given each participant's unique location and time constraints, interviews were conducted in the way which was most suitable for their situation. This resulted in three in-person interviews, two over the phone, one through email, and one using an online video conferencing platform, each according to the interviewee's preferred method. Aside from the one written interview, sessions were audio-recorded and transcribed verbatim to afford the researcher greatest ease in tracking recurring words, phrases, and ideas.

Participants. Participants were recruited by word of mouth through snowball sampling originating from the staff and faculty members at the University of St. Augustine San Marcos campus. The inclusion criteria consisted of individuals with work experience in a correctional facility; additionally, there were no gender requirements for participation. The student investigator contacted participants by means of phone call and/or email using a prepared script (see Appendix D). Participants included adults (over 18 years old) with a self-identified past or current experience working in a correctional setting. A total of seven participants were interviewed. The years of experience working within their respective correctional settings consisted of a range between one and 13 years. Job titles comprised of two correctional officers, a program supervisor, group counselor, vocational electronics instructor, a teacher's assistant, and a volunteer intern in the reintegration department. Three out of the seven participants worked in a juvenile correctional setting.

Methods of Data Collection. After recruitment, consent forms were distributed via email. The student investigator met with each participant for one interview session lasting approximately 60 minutes. Participant interviews took place either virtually or in a public agreed 
upon space. If the interview was in person, the participant identified a public space agreeing they were satisfied with the level of privacy it provided. In accordance with knowledge from the literature, the researcher posed open-ended questions that focused on the following themes regarding workplace wellness in correctional settings: environment, training, communication, safety, and stress. (See Appendix E). Information obtained from the participants were stored on the student investigator's personal computer with password protection which could only be accessed by the student investigator. For increased security, each participants' name was omitted and replaced with a number to ensure confidentiality.

\section{CHAPTER IV}

\section{Results \& Analysis}

\section{Data Analysis}

Data analysis for this project consisted of transcript coding to identify common themes and concepts derived from the transcribed data. After an initial reading of all transcripts, the student investigator assigned codes to relevant information pertaining to the research topic and previous literature. Thematic analysis was then used to interpret and derive meaning from the findings. Themes were analyzed through in-depth review and cross-reference between the transcripts to compare, contrast, and identify emerging patterns and meanings. The student investigator's mentor with extended experience in criminal justice research, then reviewed interview transcripts and cross-checked codes for confirmation, to enhance validity of the study.

\section{Results}

Upon completion of the study, four main themes relative to the health and wellness of correctional staff members emerged from the analysis of the participants' transcripts: 1) An 
overly challenging work environment; 2) A lack of institutional support; 3) Pressing safety

concerns; 4) Stress and burnout; and 5) Engaging in meaningful activities.

Theme 1: Challenging work environment. The physical work environment was found to be tough, challenging, demanding, and time-consuming for most participants due to the excessive amount of overtime shifts and/or long work shifts required. Many participants believed that being overworked restricted them from maintaining a balanced lifestyle which in-turn negatively affected their health and wellbeing.

“... we were forced to do double shift which took away our sleeping time, no time for gym for even the next day since we would have to make up the sleep from previous lost hours of sleep." - Participant \#2

“I was working 50 hours a week, sometimes 60." - Participant \#3

"First of all, you work like long hours... it wasn't uncommon for you to be asked to work 12 hours, so you work eight hours and then you're asked to stay... or even double, so do like 16 hours. So that was one thing. And then, another facility I worked, we worked seven consecutive days, 12 hours in a row... I mean it just starts to beat you up and if you're working overnight shifts, it's hard to kind of switch gears to come back into like the daytime reality. So, when you're at home you're kind of like a zombie." - Participant \#6

"There's definitely always a lot of overtime because we're always low on staff, understaffed... I remember periods where people were just like working 16-hour shifts like for days on end, you know? ... and yeah, you would hear the complaints, you would physically see the wear and tear that it does to an individual." - Participant \#7

Some participants described how the demands of their work environment negatively impacted their health and nutrition.

“... when you're in the classroom you really have to be dedicated to being in that classroom and be staying aware, so you can't really like, sit down and take a lunch break." - Participant \#1

"There were times where I literally would not be eating, you know, that'll happen at least three times out of the week where I would skip a meal because I'm so overworked... more than three times a week, to be honest, and when I would eat, 
it would have to be something that was fast and easy. So, I would drive down to the closest taco shop, or you know, to the vending machine." - Participant \#7

Social aspects such as family, friends, and home life were also negatively impacted for

some participants by the demands the facility placed on them.

"... out of the 23 officers from my academy, only 5 of the officers stayed with their significant others, and those officers quit before their relations were in serious danger, but the rest of the 18 officers had a divorce or broke-up within a couple years. I personally was a single college guy with no family at that time, but I was still having difficulty finding time to hang out with my friends since I can't make any plans due to unpredictable mandatory overtime. Not to mention, I can't make a phone call letting my friends know that I've been hit with overtime since I'm not allowed to take our phones in with us, this has ruined few friendships for me." - Participant \#2

"Some days it would really be tough when I went home, I know sometimes I was a little bit maybe on the edge, just kind of grumpy just because of some things that have happened during the day at the prison. Even my wife has made some remarks, like "ever since you started working there, you've just been really on edge" and you know depending on the individual, I think it could change a person no doubt." - Participant \#5

“... your family wants to participate and do something and you're just, you're too dang tired." - Participant \#6

The majority of participants also reported that top-down policies negatively increased their job difficulties and frustrations. Safety was always a high concern, and this oftencreated unwanted repercussions for employees of the facilities.

"There were rules that put officers in jeopardy. This could be prevented if management worked as an officer for 1-2 days. For example, in culinary they provide oranges every week, and the inmates turn them into prison made alcohol, get drunk, and begin to cause trouble. This could be fixed by giving the inmates vitamin C in a powder form." - Participant \#2

"... every once in a while, we'd ask, you know have a request for supplies, like paper, pencils, and that would just take a really long time to get kind of thing... and they have to approve every little thing... and so the kind of bureaucratic red tape that went along with that made it difficult sometimes." - Participant \#4

"It was such a bureaucracy, just trying to get anything done in there was extremely difficult. Even when I had like new equipment or new books or new 
tools for my classroom before it could come into the facility, into the classroom, you had to go through all of those different hoops to get even like a volt meter or a stool." - Participant \#5

Theme 2: Lack of institutional support. Many participants expressed their concern for the lack of support they had from the correctional facility management they worked for. Communication between staff members and their supervisors/management was sparse as participants felt there was a disconnect and a lack of understanding. Not to mention, wellness programs that facilitated their engagement in healthy activities were nonexistent.

“... the safety which puts officer's life in jeopardy that is caused by poor policy procedures.” - Participant \#2

"I felt safe and trusted around my line staff, but when it came to management stuff, I couldn't say the same thing... I have to say, generally speaking, I was not listened to." - Participant \#3

... we were trying to explain to them all the things that we go through in the classroom, but you know, they aren't really recognizing or listening to you..." - Participant \#5

"Um, I think lack of support from upper management for sure... um, overworked... and unrealistic expectations... I mean for me what I've experienced is that management was too busy on numbers and stuff. At the end of the day it comes down to the bottom line... they weren't too concerned with how the workers feel. They're just concerned about, hey, we're low on staff we need somebody to, you know." - Participant \#7

Safety training programs offered by the facility was minimal and all participants reported there were no specific training offered on how to interact with inmates.

“They did not provide any safety training at all." - Participant \#1

"I didn't really receive any training leading into it." - Participant \#4

“... quality of training was really poor. I mean we had policies like active shooter policies and stuff like that. We had a basic like how to operate a fire extinguisher. 
But I mean, if you're looking for something substantive, nothing comes to mind right now." - Participant \#7

Theme 3: Safety concerns. The majority of participants explained that the unpredictable nature of their work with respect to both the residents and the physical environment, put their safety in jeopardy and therefore caused them a lot of stress and tension. Safety programs and specialty classes offered by the facilities were very minimal and as a result, staff members reported feeling underprepared or unprepared given the unique nature of the correctional environment.

"I think one of the biggest stressors is that you just don't really know how they're going to react to things... Um, so I think just the stress of not knowing... Just like the unpredictable nature." - Participant \#1

"I mean, the job itself is stressful... you're basically standing around waiting for a fight to happen." - Participant \#3

“Inmates are always trying to manipulate... either they're always trying to intimidate you, just always trying to get into your head and mess with you and, so they could really wear you down after some time. I didn't have any real leverage, like if this guy's giving me a hard time, I could call the CO (correctional officer), and get him yanked out of class, but guess what, I'm going to have to see this dude tomorrow, you know?" - Participant \#5

Theme 4: Stress and Burnout. Generally speaking, the majority of participants agreed that working with inmates evoked emotional responses which lead to additional feelings of stress and burnout. Furthermore, there existed little to no support for these correctional facility workers, and they were unprepared to handle such a burden.

"I think the biggest stress for me was that, um, empathy factor in trying to, trying to do the best that you can do every day and not get emotionally bogged down with... I was working with the kids that were sentenced to long periods of time and I went through a really hard phase where I didn't know how to kind of emotionally digest that and still go to work and be positive." - Participant \#1 
"There's kind of like a level of guilt in a way of like, I can walk in, I walk out every day... and they're always there... and so, I think, um, that got stressful once they, you know, built connections with people and realize that they were ready to transition home and then learned that they still have 10 more years on their sentence, 20 more years of their life in prison... and it's like this is just such a waste of a life. But, um, so those kinds of emotional stressors were hard once the relationships got built..." - Participant \#3

"Um, no. I mean there were definitely days that like, it was emotionally draining because, you know, you're hearing their trauma stories a lot of the time too. And like learning why they, how they got there, like that can be really sad and really, um, hard to hear." - Participant \#4

For some, this negatively impacted how satisfied they felt with their job.

"There is so much unnecessary stress that 20 out of 23 officers quit from my academy that were much happier since they left." - Participant \#2

"To be honest, after working there for... it didn't take me long like maybe six months, it's like, man, this isn't the right place for me." - Participant \#5

Theme 5: Engaging in Meaningful Activities. With respect to stress, all participants indicated that engaging in their meaningful activities, roles, or routines helped them cope with the stressors and feelings of burnout associated with working in a correctional facility. Additionally, some participants found comfort in talking with fellow coworkers who also shared similar experiences. Recreational activities such as being out in nature, exercising, going on trips, and spending time with family and friends were all viewed as positive outlets for decompression.

"I used to swim every day after work. So, there was a lot of physical de-stressing. Um, I tried to take vacations, like a small vacation, like once a month over the weekend... or just talking to other staff or faculty and talking." - Participant \#1

"... talking to my fellow officers about all the stress they are dealing with so that I know I am not the only one..." - Participant \#2 
"... there were guys that I would call towards the end of the shift and we'd go out and have a few beers every night after work, which is not a healthy way to, I mean the socialization part is healthy... going to the beach once in a while probably would've been helpful but I didn't have that." - Participant \#3

"I was enrolled in dance classes at school. And so that was a really great outlet for me at the time. My roommate was my best friend, so talking it out pretty much kind of being my sounding board for stuff like that... I would get a coffee from the same cafe down the street every time. And so, there was something about that routine that kind of was a de-stressor after each time I went in." - Participant \#4

"Live music with friends, fishing, and Kempo (martial arts) ... just talk to other instructors about some things that I was going through.” - Participant \#5

“... back then it was just like physical activity, um, you know, physical exercise. Um, maybe hanging out with coworkers outside of work, which really isn't a great strategy, but it's something that you do right? Cause you kind of, you can talk a little bit about work..." - Participant \#6

"... my spirituality that always made me, gave me the abilities and the tools, coping skills to be able to manage my stress... for me and my particular case within my religious context, practicing rituals, prayer, meditation, sacraments, things of that nature. Um, and for me also within the realm of spirituality was the family that I have, always making sure that I build time to be present, not so much in the doing but in the being, you know." - Participant \#7

\section{CHAPTER V}

\section{Discussion \& Conclusion}

\section{Discussion}

The participants in this study described how the workplace culture of a correctional setting can have a negative impact on their health and wellbeing. On average, they viewed their work environment to be challenging and overly demanding which prevented them from maintaining a healthy and balanced lifestyle. Poor work policies, minimal to no training on safety or inmate interaction, and an overall lack of communication from the management lead to feelings of frustration, stress, and dissatisfaction within the workplace. Furthermore, emotional 
burden contributed to feelings of burnout and stress. All in all, participants found that being able to engage in their meaningful occupations outside of work was the most effective coping strategy for dealing with the negative effects of working in a correctional setting.

Results of this study are consistent with existing literature, in that it describes the unique challenges associated with the correctional profession, and areas of opportunity for both correctional facility workers and the population for which they serve. When participants in this study were asked what types of training they felt would have been most helpful for them, the majority of them highlighted the importance of communication skills and having empathy.

Compassion training and coping strategies was also noted to be of importance for others. Participant responses confirm findings from the scoping review, further indicating the high prevalence of trauma experienced by correctional staff and the need for trauma-informed care in the correctional setting.

"I think some training with how to deal with kind of the heaviness of the situation emotionally I think would be beneficial... and then some training in communicating with families..." - Participant \#1

“... communication between staff members, minors... there's ways to approach it."

- Participant \#3

"Having empathy for people in that setting is all you need to be successful..."

- Participant \#4

“...techniques to help you relax, to help you cope, you know, but, um, it wasn't there. We had to seek that out and get it kind of on our own." - Participant \#5

“... just how to communicate with people... just because I have a badge on, you know, you have to do what I say and that's not how it works... the badge isn't really important. It's just who you are and how you kind of treat folks that, you know, makes things better." - Participant \#6

“... communication skills, definitely. Um, some compassion training. So, education around that." - Participant \#7 
This study confirms that engagement in meaningful occupations, roles, and routines provide individuals with a sense of identity, purpose, and fulfillment which has the potential to mitigate negative effects associated with being in a correctional setting. Reflecting back upon the interconnectedness of worker and resident relationships, these positive benefits are likely to enhance resident health and wellbeing as well.

Despite the limited amount of research in the forensic setting, the findings of this study coincide with existing research by revealing that correctional staff experience heavy stress, fatigue, and feelings of burnout, as noted by Gould, Watson, Price, \& Valliant (2013). Additionally, the experiences shared by these participants confirm that stressors are caused by a multitude of factors that include: "the threat of violence or injury posed by inmates, working in a closed or restricted environment, and having to be in a constant state of alertness" (Brower, 2013, p. 5). The interconnected nature of resident and staff relationships, warrants that the needs of correctional staff members health and wellness should be explored in order to improve job performance and satisfaction. Existing literature indicates a positive impact on workplace culture as a whole, has the potential to enhance the residents' success as well. Lehman, Greener, Rowan-Szal, and Flynn (2012), discovered a high demand for increasing the quantity and quality of treatment programs in correctional settings. "Difficulty recruiting, training, and retaining qualified staff, as well as frequent conflict between therapeutic and security concerns" were noted to be some of the major factors that contribute to a lack of effective programs for residents. (Lehman et al., 2012, p. 10).

\section{Limitations}

Despite having gained in-depth knowledge on the individual experiences associated with workplace wellness in correctional settings, several limitations exist in this study. First and 
foremost, the qualitative nature of this study yields purely subjective findings. Each participant's experience is dependent upon their specific job title, years of experience, and the particular correctional facility at which they worked for. Moreover, convenient sampling methods along with a small sample size is likely to limit the power of inferences with respect to a larger population. This study did not include specific inclusion and exclusion criteria for specific professions within the correctional field, years of work experience, or the amount of time passed since last employed at respective said facilities. Due to the varying locations of participants and their time constraints, not all interviews were able to be conducted face-to-face. Therefore, responses could vary as the delivery of interviews were not consistent. Lastly, member checking was not used to determine the accuracy of the qualitative findings with participants. Member checking would have provided the participants an opportunity to comment and/or confirm that the findings are indeed true, thus improving the validity of this study.

\section{Implications for Occupational Therapy}

Current literature confirms that the role of occupational therapy within the forensic setting continues to be an emerging practice area. Much of the existing literature focuses on treatment for the residents and depicts correctional facilities as a restrictive environment which inhibits occupational performance. However, little has been said about programs for the staff members who are also known to suffer from occupational deprivation.

Upon examining existing literature on occupational therapy’s involvement with correctional facility staff members, Wagenfeld et al. (2017) explored the relationship between one's interaction with nature and self-perception of stress for correctional system staff. Results found that correctional staff used time outdoors to cope with stress. According to Wagenfeld et al. (2017), the majority of correctional staff surveyed mentioned that they would benefit from an 
outside decompression area at their institution; this was especially the case for those who used outdoor time as a coping strategy and for those who preferred to go outside during their work breaks. Findings of this study highlight the impact environmental modifications can have, and further support the need for health-promoting policies and programs. Occupational therapists are equipped with the necessary skill-set to influence the health of individuals, populations, and organizations through collaboration, education, and advocacy. Occupational therapists also possess the ability to improve the physical, mental, and social aspects of individual's lives and work to implement change by examining factors associated with overcoming barriers and enhancing occupational performance (AOTA, 2014). Thus, occupational therapists are uniquely positioned to assist in this environment.

Occupational therapists can assume a consultative role to deliver client-centered interventions to correctional staff members. Interventions can focus on facilitating optimal occupational engagement by the use of assessments such as the COPM to identify each individual's unique needs, strengths, and limitations. Consultation can also be offered in the form of group training sessions to provide useful techniques in stress management and optimizing engagement in meaningful activities and routines to enhance overall wellbeing. In effort to address stress and burnout, consultative services can more specifically include techniques for relaxation, and effective coping strategies. Additionally, when addressing workplace challenges such as, lack of support, services can focus on facilitating effective communication within the institution by changing the employer's focus to a more employee first perspective. Occupational therapy practitioners are particularly useful in this setting because they are well versed in providing a comprehensive assessment of the multidimensional nature of 
residents and staff relationships as it relates to their specific performance patterns, skills, client factors, contexts and environments (AOTA, 2014).

In an effort to expand upon research in forensic settings, future research can further examine the relationships between inmates and staff. A mixed methods review using surveys and focus groups can generate a greater sample size and expand upon the existing research. Future studies can also benefit from focusing on a specific job title for a particular population of residents; such as correctional officers for the adult incarcerated population. In contrast, a study looking at one particular facility and assessing the needs of all staff members of different roles can provide even more valuable information on the organizational climate unique to that facility to improve workplace culture.

Future projects can focus on advocating for the role of occupational therapy in a correctional facility. A needs assessment can be performed with not only the staff, but also with residents to understand both perspectives on occupational deprivation and how they impact one another. Further understanding here can lead to development and implementation of a program that promotes occupational enrichment for this unique population. As an example, occupational therapists could aid in enrichment by providing a wellness program which includes gardening, yoga, and meditation as a part of workplace routine for stress management. Furthermore, occupational therapists can advocate for health-promoting policies that encourage health and fitness; this could include: offering free physical checkups for staff, gym memberships, and staff outings to promote physical activity and fellowship amongst coworkers.

Findings of this study provide support for the advancement of occupational therapy in the correctional setting. As such, this manuscript has the potential to be published in journals such as: The Journal of Offender Rehabilitation, American Journal of Occupational Therapy, and 
Occupational Therapy in Mental Health. However, the Journal of Offender Rehabilitation would be most appropriate for the dissemination of this study to inform other practitioners, educators, and researchers involved in the criminal justice setting about the role of occupational therapy. This multidisciplinary, international peer-reviewed journal focuses on the research and analysis of criminal justice program policies, practices, and services. Similarly, this study also meets the standard of being an original qualitative research that looks to improve correctional policies and practice. Additional information regarding submission can be found in Appendix F.

\section{Conclusion}

This study provides insight into the experiences of 7 individuals who had previous firsthand experience working in a correctional setting. Workplace culture related to health and wellness are discussed where participants disclose negative effects the environment posed to their wellbeing which in turn impacted their job satisfaction. Correctional settings prove not only to be restrictive to inmates, but also to staff members as they limit access to meaningful occupations, roles, and routines. Job demands linked to poor work policies and interaction with inmates are also found to take a toll physically, mentally, and emotionally which further exacerbates symptoms of stress, fatigue, and burnout. As such, the results of this study are found to be consistent with previous literature on correctional staff members. Furthermore, these factors may generalize to other correctional settings where staff members are also likely to be deprived of their health-promoting roles, routines, and occupations. In closing, occupational therapists are uniquely equipped with the necessary skills to examine and enhance workplace wellness in correctional settings, thereby improving overall well-being and quality of life for residents and staff alike. 


\section{References}

American Occupational Therapy Association. (2014). Occupational therapy practice framework: Domain and process (3rd ed.). American Journal of Occupational Therapy, 68(Suppl. 1), S1-S48.

Bowser, A., Link, W., Dickson, M., Collier, L. and Donovan-Hall, M. (2017). A qualitative study exploring the causes of boredom for men with a psychosis in a forensic setting. Occupational Therapy in Mental Health, 34(1), pp.32-48.

Brower, J. (2013). Correctional officer wellness and safety literature review. Washington, DC: U.S. Department of Justice Office of Justice Programs Diagnostic Center. Retrieved from: www. ojpdiagnosticcenter.org/sites/default/files/spotlight/download/ NDC CorrectionalOfficerWellnessSafety Lit Review.pdf.r

Boyt Schell, B., Gillen, G., Scaffa, M. and Cohn, E. (2014). Willard \& Spackman's occupational therapy. 12th ed. Philadelphia: Wolters Kluwer Health/Lippincott Williams \& Wilkins.

Bureau of Justice Statistics (2016). Key Statistic: Incarceration rate. [online] Retrieved from https://www.bjs.gov/index.cfm?ty=kfdetail\&iid $=493$

Corring D, Cook J (1999). Client-centered care means that I am a valued human being. Canadian Journal of Occupational Therapy 66(2): 71-82. DOI:10.1177/ 000841749906600203.

Crabtree, J., Ohm, D., Wall, J. \& Ray, J. (2016). Evaluation of a prison occupational therapy informal education program: A pilot study. Occupational Therapy International, 23(4), pp.401-411.

Creswell, J. (2014). Research design: qualitative, quantitative, and mixed methods approaches (4th ed.). Los Angeles: SAGE Publications, Inc. 
Duncan, E. A., Munro, K., \& Nicol, M. M. (2003). Research priorities in forensic occupational therapy. British Journal of Occupational Therapy, 66(2), 55-64.

Durose, M., Cooper, A., \& Snyder, H. (2014). Recidivism of prisoners released in 30 states in 2005: Patterns from 2005 to 2010 (pdf, 31 pages), Bureau of justice statistics special report, April 2014, NCJ 244205.

Eggers, M., Muñoz, J., Sciulli, J., \& Crist, P. (2006). The community reintegration project: Occupational therapy at work in a county jail. Occupational Therapy in Health Care, $20(1), 17-37$.

Foss, A. (2016). A prosecutor's vision for a better justice system. [online] Ted.com. Available at: https://www.ted.com/talks/adam_foss_a_prosecutor_s_vision_for_a_better_justice_syste m [Accessed 27 Jan. 2019].

Gould, D. D., Watson, S. L., Price, S. R., \& Valliant, P. M. (2013). The relationship between burnout and coping in adult and young offender center correctional officers: An exploratory investigation. Psychological Services, 10(1), 37-47. https://doi-org.prxusa.lirn.net/10.1037/a0029655

Journal of Offender Rehabilitation. (2019). Retrieved 12 August 2019, from https://www.tandfonline.com/action/authorSubmission?journalCode=wjor20\&page=instr uctions

Keilhofner, G. (2008). The model of human occupation: Theory and application (4th ed.). Baltimore, MD: Wolters Kluwer.

Lehman, W., Greener, J., Rowan-Szal, G. and Flynn, P. (2012). Organizational readiness for change in correctional and community substance abuse programs. Journal of Offender 
Rehabilitation, [online] 51(1-2), pp.96-114. Available at:

https://www.ncbi.nlm.nih.gov/pmc/articles/PMC3325111/.

Law M, Cooper B, Strong S, Stewart D, Rigby P, Letts L (1996). The person-environmentoccupation model: A transactive approach to occupational performance. Canadian Journal of Occupational Therapy 66: 9-23.

Morgan, W. (2009). Correctional officer stress: A review of the literature 1977-2007. American Jails, 23(2), 33-34.

Munoz, J. (2011). Mental Health Practice in Forensic Settings. In C. Brown \& V. Stoffel (Eds.), Occupational therapy in mental health (pp 526-545). Philadelphia [Pa.]: F.A. Davis Co.

Muñoz, J., McTish, J., Ruggeri, J., Phillips, G. and Catalano, A. (2017). Occupational therapy's role in the criminal justice system: A scoping review. American Journal of Occupational Therapy, 71(4_Supplement_1), pp.7111520314p1.

Muñoz, J. P., Moreton, E. M., \& Sitterly, A. M. (2016). The scope of practice of occupational therapy in U.S. criminal justice settings. Occupational Therapy International, 23(3), 241-254. https://doi-org.prx-usa.lirn.net/10.1002/oti.1427

National Institute of Justice. (2018). Recidivism | National Institute of Justice. [online] Available at: https://www.nij.gov/topics/corrections/recidivism/Pages/welcome.aspx

O'Connell, M., \& Farnworth, L. (2007). Occupational therapy in forensic psychiatry: A review of the literature and a call for a united and international response. British Journal of Occupational Therapy, 70(5), 184-191.

Portney, L. \& Watkins, M. (2015). Foundations of Clinical Research: Application to Practice (3rd Ed). F.A. Davis. Philadelphia, PA. ISBN 9780803646575. 
Schaufeli, W. B., \& Peeters, M. C. (2000). Job stress and burnout among correctional officers: A literature review. International Journal of Stress Management, 7, 19-48. doi:10.1023/ A:1009514731657

The Sentencing Project (2017). Criminal Justice Facts. [online] Retrieved from https:/www.sentencingproject.org/criminal-justice-facts/

Wagenfeld, A., Stevens, J., Toews, B., Jarzembowski, S., Ladjahasan, N., Stewart, J. and Raddatz, C. (2017). Addressing correctional staff stress through interaction with nature: A new role for occupational therapy. Occupational Therapy in Mental Health, 34(3), pp.285-304.

World Prison Brief (2019). World Prison Population List. [online] Retrieved from http://www.prisonstudies.org/sites/default/files/resources/downloads/wppl_12.pdf

Yuancie, L. (2017). Does working reduce recidivism? How jobs affect the likelihood of returning to prison. Alaska Economic Trends, 37(6), 4-8. 
APPENDIX A

Proposed Observational Data Collection Form 


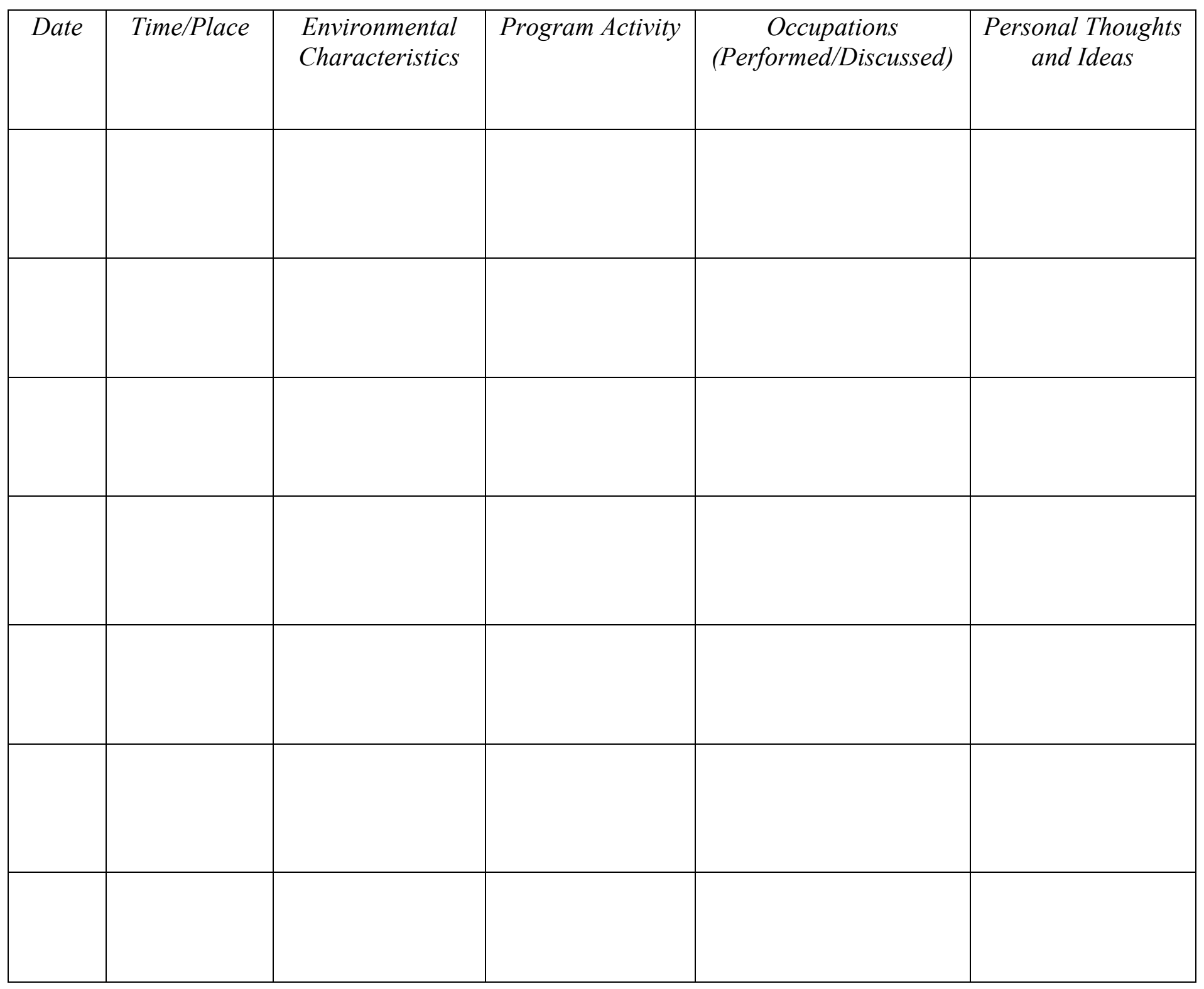




\section{APPENDIX B}

Proposed Staff Interview Questions 
1. What do you believe are the greatest needs your residents demonstrate?

a. What are the factors affecting these needs?

2. What goals have your residents expressed to you?

a. How do you feel they are being addressed?

3. What are the greatest barriers that you think your residents will face in meeting these goals?

4. What is your current job title and responsibilities at this facility?

5. What does a typical day of work entail?

6. Describe the working relationship between coworkers here

a. How well does everyone work together?

b. How would you describe the level of teamwork?

7. How satisfied are you with your job?

8. What do you find most effective about the re-entry program here?

9. What do you find the least effective? (if any)

10. Is there anything you personally would like to see being addressed here within the programs?

11. Is there any stress associated with your job?

a. If so, what are the main contributing factors?

b. And what are the three most common ways you deal with it?

12. What do you enjoy doing in your free time? Any hobbies? 
APPENDIX C

Proposed Resident Interview Questions 
1. Are you currently employed?
a. If so, what do you do?
b. Do you enjoy your work?

2. If not currently employed, what type of job would you find most enjoyable for you and why?

3. What are some strengths that you believe you possess?

4. What do you enjoy doing in your free time? Any hobbies?

5. What occupies the majority of your time?

6. What do you find most helpful about this facility and the programs they offer here?

7. What do you find the least helpful? (if any)

8. If there anything you personally would like to address or work on in the programs here?

9. What goals do you have for yourself?

10. What are your needs in terms of trying to meet these goals?

a. Do you feel supported?

11. Do you find the current programs useful in helping you meet your goals?

12. What are your greatest concerns for when you leave this facility?

a. Is there support for your transition?

b. Do you feel prepared to re-enter society? (mentally, physically, emotionally) 
APPENDIX D

Email Script 
To Whom This May Concern,

My name is Maxwell Sand, and I am a third-year doctorate student at the University of St. Augustine (San Marcos campus). I received your contact information from (name of faculty/staff connection). I am reaching out to you with respect to my capstone project regarding the assessment of workplace wellness in the correctional settings. The purpose of this study is to explore the needs of correctional staff members in addressing their health and wellness. I am hoping to talk to people who currently work or have worked in the past in correctional settings (any role). This study would consist of an interview (phone, virtual, or in person) lasting approximately 60 minutes.

If you are willing to talk, please let me know if you would prefer to have this meeting via phone, virtual medium (i.e. zoom) or in person? Also, if you would like to meet in person, what location would be best for you? Finally, can you please provide me with your best contact information and let me know some times that will work for you these upcoming weeks? I can be available Monday through Sunday by appointment.

Additionally, I am available to answer any questions you have and am thankful for any interest in assisting me with this project.

Warmest Regards,

Maxwell K. Sand, OTD/S, Student Principal Investigator

Occupational Therapy, Class of 2019

Phone: 808-259-1924

E-mail: m.sand@usa.edu 
APPENDIX E Actual Interview Questions 
1. What was/is your current job title and responsibilities at this facility?

a. Did/do you feel supported?

2. How did you become involved in this line of work?

3. What is your educational background?

4. What was it like being a new employee at this facility?

5. What did/does a typical day of work entail?

a. Describe your role in working with clients/individuals incarcerated.

6. Describe the working relationship between coworkers at your past/current facility

a. How well did/does everyone work together?

b. How would you describe the level of teamwork?

7. How was/is the communication between workers and management?

a. Were/are there any issues with communication? Is so, what?

8. Were/are there any policies or rules that made/make your job difficult or easier to perform? If so, describe them.

9. Were/are there any safety programs at the facility that were helpful? If so, what and how?

10. How concerned were/are you about your safety at the facility?

a. Did/does this affect your satisfaction with your job? If yes, in what ways?

b. If yes, how did/do you address these concerns?

11. Overall, how satisfied were/are you with your job?

12. What part of your training has been the most helpful for working in this setting?

a. Was/is there anything you learned outside of training that has been helpful for your job?

b. Is there any other types of training that you feel would be helpful? If so, what? 
13. Were/are there any wellness programs at the facility that facilitated your engagement in healthy activities while at work? If so, what?

a. Were/are there any aspects of the physical environment or company policies that promote health and/or fitness?

14. Were/are there any aspects of your work or workplace environment that inhibit your ability maintain good health? If so, what?

15. Was/is there any stress associated with your job?

a. If so, what were/are the main contributing factors?

b. What were/are the three most common ways you dealt/deal with it?

16. What did/do you enjoy doing in your free time while working at said facility? Any hobbies?

17. Did/do any aspects of your work prevent you from engaging in healthy activities outside of the workplace?

a. What factors of this job affect your health and nutrition?

b. What factors affect how you feel at home and/or your family life?

18. What did/do you believe were/are the greatest needs your residents demonstrated/demonstrate?

a. What were/are the factors affecting these needs?

19. What concerns have your residents expressed to you?

a. How do you feel they were/are being addressed?

b. What were/are the greatest barriers that you think your residents faced/will face in addressing these concerns?

20. What did/do you find most effective about the programs for the residents there? 
21. What did/do you find the least effective? (if any)

22. Was/is there anything you personally would have liked or currently like to see being addressed within the programs?

23. Do you feel that you changed as a person after working here? If so, in what ways? 


\section{APPENDIX F}

Instructions for Journal Publication 


\section{Instructions for authors}

Thank you for choosing to submit your paper to us. These instructions will ensure we have everything required so your paper can move through peer review, production and publication smoothly. Please take the time to read and follow them as closely as possible, as doing so will ensure your paper matches the journal's requirements. For general guidance on the publication process at Taylor \& Francis please visit our Author Services website.

This journal uses ScholarOne Manuscripts (previously Manuscript Central) to peer review manuscript submissions. Please read the guide for ScholarOne authors before making a submission. Complete guidelines for preparing and submitting your manuscript to this journal are provided below.

\section{About the Journal}

Journal of Offender Rehabilitation is an international, peer-reviewed journal publishing highquality, original research. Please see the journal's Aims \& Scope for information about its focus and peer-review policy.

Please note that this journal only publishes manuscripts in English.

Journal of Offender Rehabilitation accepts the following types of article: original articles.

The Journal of Offender Rehabilitation is a multidisciplinary, peer-reviewed journal presenting empirical research and critical analyses of criminal justice program policies, practices, and services. The journal serves as a professional resource for practitioners, educators and researchers who work with individuals involved in the criminal justice system and study the dynamics of rehabilitation and individual and system change. Original research using qualitative or quantitative methodology, theoretical discussions, evaluations of program outcomes, and state of the science reviews will be considered. A primary journal focus is the use of research to inform and improve correctional policies and practice, with articles clearly defining the theoretical and empirical basis for program models and establishing connections between research findings and needed interventions and services. Programs and services for correctional populations residing in prison, as well as in the community, are examined. The range of topics included in the journal is broad and encompasses alternatives to incarceration; community reentry and reintegration; alcohol, substance abuse and mental health treatment interventions; services for correctional populations with special needs; recidivism prevention strategies; educational and vocational programs; families and incarceration; culturally appropriate practice and probation and parole services. Please note that Journal of Offender Rehabilitation uses CrossCheck ${ }^{\mathrm{TM}}$ software to screen papers for unoriginal material. By submitting your paper to Journal of Offender Rehabilitation you are agreeing to any necessary originality checks your paper may have to undergo during the peer review and production processes. Submitting a Manuscript. Journal of Offender Rehabilitation receives all manuscript submissions electronically via its ScholarOne Manuscripts website located at: http://mc.manuscriptcentral.com/WJOR. 
ScholarOne Manuscripts allows for rapid submission of original and revised manuscripts, as well as facilitating the review process and internal communication between authors, editors, and reviewers via a web-based platform. ScholarOne Manuscripts technical support can be accessed via: http://scholarone.com/services/support. If you have any questions please contact the journal's editor, Creasie Finney Hairston, $\mathrm{PhD}$, Dean and Professor, Jane Addams College of Social Work, University of Illinois at Chicago, at: journal@uic.edu. Manuscripts should be limited to 25 pages maximum. Each manuscript must be accompanied by a statement that it has not been published elsewhere and that it has not been submitted simultaneously for publication elsewhere. As an author you are required to secure permission if you want to reproduce any figure, table or extract text from any other source. This applies to direct reproduction as well as "derivative reproduction" (where you have created a new figure or table which derives substantially from a copyrighted source). All accepted manuscripts, artwork, and photographs become the property of the publisher. All parts of the manuscript should be typewritten, doublespaced, with margins of at least one inch on all sides. Number manuscript pages consecutively throughout the paper. Authors should also supply a shortened version of the title suitable for the running head, not exceeding 50 character spaces. Each article should be summarized in an abstract of not more than 100 words. Please list 5 or 6 keywords that identify manuscript content. Avoid abbreviations, diagrams, and reference to the text in the abstract. Be sure to include an updated corresponding address and e-mail for each author.

\section{Peer Review and Ethics}

Taylor \& Francis is committed to peer-review integrity and upholding the highest standards of review. Once your paper has been assessed for suitability by the editor, it will then be double blind peer reviewed by independent, anonymous expert referees. Find out more about what to expect during peer review and read our guidance on publishing ethics.

\section{Preparing Your Paper}

\section{Structure}

Your paper should be compiled in the following order: title page; abstract; keywords; main text introduction, materials and methods, results, discussion; acknowledgments; declaration of interest statement; references; appendices (as appropriate); table(s) with caption(s) (on individual pages); figures; figure captions (as a list).

\section{Word Limits}

Please include a word count for your paper.

A typical paper for this journal should be no more than 25 pages. 


\section{Style Guidelines}

Please refer to these quick style guidelines when preparing your paper, rather than any published articles or a sample copy.

Please use American spelling style consistently throughout your manuscript.

Please use double quotation marks, except where "a quotation is 'within' a quotation". Please note that long quotations should be indented without quotation marks.

\section{Formatting and Templates}

Papers may be submitted in Word format. Figures should be saved separately from the text. To assist you in preparing your paper, we provide formatting template(s).

Word templates are available for this journal. Please save the template to your hard drive, ready for use.

If you are not able to use the template via the links (or if you have any other template queries) please contact us here.

\section{References}

Please use this reference guide when preparing your paper.

\section{Taylor \& Francis Editing Services}

To help you improve your manuscript and prepare it for submission, Taylor \& Francis provides a range of editing services. Choose from options such as English Language Editing, which will ensure that your article is free of spelling and grammar errors, Translation, and Artwork Preparation. For more information, including pricing, visit this website.

\section{Checklist: What to Include}

1. Author details. All authors of a manuscript should include their full name and affiliation on the cover page of the manuscript. Where available, please also include ORCiDs and social media handles (Facebook, Twitter or LinkedIn). One author will need to be identified as the corresponding author, with their email address normally displayed in the article PDF (depending on the journal) and the online article. Authors' affiliations are the affiliations where the research was conducted. If any of the named co-authors moves affiliation during the peer-review process, the new affiliation can be given as a footnote. Please note that no changes to affiliation can be made after your paper is accepted. Read more on authorship.

2. Should contain an unstructured abstract of 200 words.

3. You can opt to include a video abstract with your article. Find out how these can help your work reach a wider audience, and what to think about when filming. 
4. Read making your article more discoverable, including information on choosing a title and search engine optimization.

5. Funding details. Please supply all details required by your funding and grant-awarding bodies as follows:

For single agency grants

This work was supported by the [Funding Agency] under Grant [number xxxx].

For multiple agency grants

This work was supported by the [Funding Agency \#1] under Grant [number xxxx]; [Funding Agency \#2] under Grant [number xxxx]; and [Funding Agency \#3] under Grant [number xxxx].

6. Disclosure statement. This is to acknowledge any financial interest or benefit that has arisen from the direct applications of your research. Further guidance on what is a conflict of interest and how to disclose it.

7. Biographical note. Please supply a short biographical note for each author. This could be adapted from your departmental website or academic networking profile and should be relatively brief (e.g., no more than 200 words).

8. Data availability statement. If there is a data set associated with the paper, please provide information about where the data supporting the results or analyses presented in the paper can be found. Where applicable, this should include the hyperlink, DOI or other persistent identifier associated with the data set(s). Templates are also available to support authors.

9. Data deposition. If you choose to share or make the data underlying the study open, please deposit your data in a recognized data repository prior to or at the time of submission. You will be asked to provide the DOI, pre-reserved DOI, or other persistent identifier for the data set.

10. Supplemental online material. Supplemental material can be a video, dataset, fileset, sound file or anything which supports (and is pertinent to) your paper. We publish supplemental material online via Figshare. Find out more about supplemental material and how to submit it with your article.

11. Figures. Figures should be high quality (1200 dpi for line art, 600 dpi for grayscale and 300 dpi for color, at the correct size). Figures should be supplied in one of our preferred file formats: EPS, PDF, PS, JPEG, TIFF, or Microsoft Word (DOC or DOCX) files are acceptable for figures that have been drawn in Word. For information relating to other file types, please consult our Submission of electronic artwork document.

12. Tables. Tables should present new information rather than duplicating what is in the text. Readers should be able to interpret the table without reference to the text. Please supply editable files.

13. Equations. If you are submitting your manuscript as a Word document, please ensure that equations are editable. More information about mathematical symbols and equations.

14. Units. Please use SI units (non-italicized).

\section{Using Third-Party Material in your Paper}

You must obtain the necessary permission to reuse third-party material in your article. The use of short extracts of text and some other types of material is usually permitted, on a limited basis, for the purposes of criticism and review without securing formal permission. If you wish to include any material in your paper for which you do not hold copyright, and which is not covered by this informal agreement, you will need to obtain written permission from the copyright owner prior to submission. More information on requesting permission to reproduce work(s) under copyright. 


\section{Submitting Your Paper}

This journal uses ScholarOne Manuscripts to manage the peer-review process. If you haven't submitted a paper to this journal before, you will need to create an account in ScholarOne. Please read the guidelines above and then submit your paper in the relevant Author Center, where you will find user guides and a helpdesk.

Please note that Journal of Offender Rehabilitation uses Crossref ${ }^{\mathrm{TM}}$ to screen papers for unoriginal material. By submitting your paper to Journal of Offender Rehabilitation you are agreeing to originality checks during the peer-review and production processes.

On acceptance, we recommend that you keep a copy of your Accepted Manuscript. Find out more about sharing your work.

\section{Data Sharing Policy}

This journal applies the Taylor \& Francis Basic Data Sharing Policy. Authors are encouraged to share or make open the data supporting the results or analyses presented in their paper where this does not violate the protection of human subjects or other valid privacy or security concerns.

Authors are encouraged to deposit the dataset(s) in a recognized data repository that can mint a persistent digital identifier, preferably a digital object identifier (DOI) and recognizes a longterm preservation plan. If you are uncertain about where to deposit your data, please see this information regarding repositories.

Authors are further encouraged to cite any data sets referenced in the article and provide a Data Availability Statement.

At the point of submission, you will be asked if there is a data set associated with the paper. If you reply yes, you will be asked to provide the DOI, pre-registered DOI, hyperlink, or other persistent identifier associated with the data set(s). If you have selected to provide a preregistered DOI, please be prepared to share the reviewer URL associated with your data deposit, upon request by reviewers.

Where one or multiple data sets are associated with a manuscript, these are not formally peer reviewed as a part of the journal submission process. It is the author's responsibility to ensure the soundness of data. Any errors in the data rest solely with the producers of the data set(s).

\section{Publication Charges}

There are no submission fees, publication fees or page charges for this journal.

Color figures will be reproduced in color in your online article free of charge. If it is necessary for the figures to be reproduced in color in the print version, a charge will apply. 
Charges for color figures in print are $\$ 400$ per figure ( $£ 300 ; \$ 500$ Australian Dollars; $€ 350$ ). For more than 4 color figures, figures 5 and above will be charged at $\$ 75$ per figure ( $£ 50 ; \$ 100$ Australian Dollars; $€ 65$ ). Depending on your location, these charges may be subject to local taxes.

\section{Copyright Options}

Copyright allows you to protect your original material and stop others from using your work without your permission. Taylor \& Francis offers a number of different license and reuse options, including Creative Commons licenses when publishing open access. Read more on publishing agreements.

\section{Complying with Funding Agencies}

We will deposit all National Institutes of Health or Wellcome Trust-funded papers into PubMedCentral on behalf of authors, meeting the requirements of their respective open access policies. If this applies to you, please tell our production team when you receive your article proofs, so we can do this for you. Check funders' open access policy mandates here. Find out more about sharing your work.

\section{Open Access}

This journal gives authors the option to publish open access via our Open Select publishing program, making it free to access online immediately on publication. Many funders mandate publishing your research open access; you can check open access funder policies and mandates here.

Taylor \& Francis Open Select gives you, your institution or funder the option of paying an article publishing charge (APC) to make an article open access. Please

contact openaccess@tandf.co.uk if you would like to find out more, or go to our Author Services website.

For more information on license options, embargo periods and APCs for this journal please go here.

\section{My Authored Works}

On publication, you will be able to view, download and check your article's metrics (downloads, citations and Altmetric data) via My Authored Works on Taylor \& Francis Online. This is where you can access every article you have published with us, as well as your free eprints link, so you can quickly and easily share your work with friends and colleagues.

We are committed to promoting and increasing the visibility of your article. Here are some tips and ideas on how you can work with us to promote your research. 


\section{Article Reprints}

You will be sent a link to order article reprints via your account in our production system. For enquiries about reprints, please contact Taylor \& Francis at reprints@taylorandfrancis.com. You can also order print copies of the journal issue in which your article appears.

\section{Queries}

Should you have any queries, please visit our Author Services website or contact us here.

*Submission guidelines obtained from: Journal of Offender Rehabilitation. (2019).

https://www.tandfonline.com/action/authorSubmission?journalCode=wjor20\&page=instructions 